\title{
Masculinidade e homoerotismo no Império português seiscentista: as aventuras sodomíticas do Padre Frutuoso Álvares, vigário do Matoim
}

Cássio Bruno de Araujo Rocha*

Resumo: $\mathrm{O}$ artigo analisa os cruzamentos entre gênero e sexualidade, problematizando a questão da sodomia em relação a uma vivência performativa da masculinidade na América portuguesa do século XVI. Usando conceitos de Judith Butler e Raweyn Connell, investigo como a masculinidade e o homoerotismo interagiram na vida do padre Frutuoso Álvares, que se confessou ao visitador Heitor Furtado de Mendonça na Primeira Visitação do Santo Ofício da Inquisição. Em meio à análise, discorro sobre as polêmicas que envolvem a categoria da sodomia, tanto em uma perspectiva teórica, abordando o debate entre as correntes essencialista e construcionista sobre a natureza do homoerotismo, da homossexualidade e da sodomia, quanto em um viés histórico, contextualizando os múltiplos significados da categoria sodomia na cultura europeia cristã até o século XVI.

Palavras-chaves: Masculinidade; homoerotismo; Inquisição

Abstract: The article analyzes the interceptions between gender and sexuality, questioning the problem of sodomy in relation to a masculinity performativity experience in the Portuguese America on the XVI century. Through concepts by Judith Butler and Raweyn Connell, I investigated how masculinity and homoeroticism interacted in the life of padre Frutuoso Álvares, who confessed to the visitador Heitor Furtado de Mendonça in the first Visitação of the Holy Office of the Inquisition. During this analysis, I disserted about the polemics that surround the category of sodomy in a theoretical perspective addressing the debate between the essentialist and constructionist schools about the nature of homoeroticism, homosexuality and sodomy; Moreover in a historical perspective contextualizing the multiple meanings of sodomy in European culture until the XVI century.

Key-words: Masculinity; homoeroticism; Inquisition.

\footnotetext{
"Mestrando pelo Programa de Pós-graduação em História da Universidade Federal de Minas Gerais. Email para contato: caraujorocha@gmail.com.
} 
Com o presente artigo, analiso algumas relações entre gênero se sexualidade a partir da problematização das práticas de masculinidade performatizadas pelo padre Frutuoso Álvares, que viveu no Império português no século XVI e foi condenado pelo Santo Ofício durante a primeira Visitação inquisitorial à América Portuguesa na década de 1590, em função de suas experiências sexuais homoeróticas, caracterizadas, no contexto, como sodomíticas. ${ }^{1}$ Antes, contudo, de iniciar a análise, é necessário tomar três breves desvios à rota estabelecida. Em primeiro lugar, precisarei o objeto da investigação, esclarecendo quais práticas sodomíticas serão trabalhadas. Em seguida, abordarei os conceitos de performatividade de gênero e de masculinidade que baseiam o estudo. Em terceiro lugar, finalmente, definirei, em linhas gerais, o contexto em que o protagonista dessa investigação se viu envolvido com o Tribunal do Santo Ofício da Inquisição.

Assim, em primeiro lugar cabe delimitar a interrogação que guia esse trabalho, fazendo algumas ressalvas em relação ao objeto. A sodomia será trabalhada especificamente a partir das experiências do padre Frutuoso Álvares, um português nascido na cidade de Braga na primeira metade do século XVI. Assim, o homoerotismo que o padre praticou foi significado por ele (e pela Inquisição) a partir do arcabouço cultural europeu e cristão - sendo ele que pretendo examinar.

Como detalharei a seguir, a categoria de sodomia tinha significados movediços na cultura europeia moderna, com teólogos, moralistas e inquisidores definindo-a de modo mais ou menos abrangente de acordo com o contexto. Segundo Ligia Bellini, a sodomia significou tanto o sexo anal (inclusive entre homem e mulher), quanto a cópula entre pessoas do mesmo sexo, podendo inclusive se confundir com outros pecados, como o bestialismo e a molície (BELLINI, 1989: 71-92). Para efeitos do presente trabalho, restrinjo-me à sodomia em sua forma mais perfeita, aquela praticada entre dois homens com penetração anal e ejaculação intra vas - pois foi essa a forma predileta do padre Frutuoso e de seus amantes.

O segundo desvio é de natureza conceitual. Trabalho com a categoria de gênero conforme a conceituação de Judith Butler, que a estabelece por meio da noção de performatividade. O gênero, à luz do pensamento butleriano, pode ser definido como uma repetição de atos performativos sem autor ou ator anteriores a ela mesma; sendo a cotidiana

\footnotetext{
${ }^{1}$ Necessária à análise da relação entre gênero e sexualidade aqui proposta é a problematização da categoria de sodomia no período moderno, ao qual será feita a partir da confissão feita pelo padre Frutuoso Álvares na Primeira Visitação e do processo instaurado contra ele pelo visitador Heitor Furtado de Mendonça a partir da denúncia de Jerônimo de Parada. O processo encontra-se digitalizado no site dos Arquivos Nacionais da Torre do Tombo em Lisboa, sendo seu índice de referência PT-TT-TSO/IL/28/5846. Disponível em: http://ttonline.dgarq.gov.pt/dserve.exe?dsqServer=calm6\&dsqIni=Dserve.ini\&dsqApp=Archive \&dsqCmd=show $. t c l \& d s q D b=C$ atalog $\&$ dsqPos=34\&dsqSearch $=((($ text $)=$ 'frutuoso')AND((text)='alvares')). Último acesso em: 10 de outubro de 2013.
} 
repetição performativa a produtora dos gêneros na medida mesmo em que os expressa, compondo a ilusão da interioridade do gênero na e sobre a superfície dos corpos assim generificados. Portanto, o conceito de performatividade de gênero compreende esses atos que realizam, em seu acontecer cotidiano, os gêneros. Esses atos são performativos no sentido de que a essência ou a identidade que pretendem expressar são construtos, feitos e embasados por signos corpóreos e outros meios discursivos. Sendo um efeito de atos performativos em permanente e corriqueira repetição, o gênero não é uma instância original ou uma categoria a ser atingida, antes é uma cópia destinada ao fracasso, uma vez que a sua substância, por não ser mais que uma fantasia corporificada, não é jamais atingida por quem quer que seja. É o destino fracassado do gênero que produz a coerção de uma perfomatividade sempre reiterada do gênero (BUTLER, 2012: 185-201).

Tendo como foco os processos e as relações pelos quais homens e mulheres vivem existências generificadas, a masculinidade pode ser definida como, simultaneamente, um local nas relações de gênero, as práticas pelas quais homens e mulheres engajam este lugar ao gênero e os efeitos destas práticas em experiências corporais, de personalidade e de cultura (CONNELL, 2005: 71).

Masculinidades e feminilidades são projetos de gênero, processos de configuração de práticas sociais no tempo e que transformam seus pontos de partida em estruturas de gênero. Enquanto configurações de práticas, masculinidades e feminilidades posicionam-se, ao mesmo tempo, em várias estruturas relacionais, que podem decorrer de diferentes trajetórias históricas. São, por conseguinte, sujeitas à contradições internas e à rupturas (CONNELL, 2005:72-73).

O conceito de masculinidades, conforme apresentado por Connell, é passível de articulação ao de performatividade de gênero. Segundo Miguel Vale de Almeida, a compreensão da masculinidade exige que o pesquisador atente para seus aspectos discursivo e performativo, ou seja, para a expressão verbal, incorporada ou ritualizada de valorações morais sobre o que é ser homem e o que é ser mulher, baseados numa divisão do mundo primariamente alicerçada sobre a dicotomia dos sexos (ALMEIDA, 2000:16).

Finalmente, o terceiro desvio refere-se ao contexto histórico da investigação, o que passa pela história da atuação da Inquisição portuguesa na América. Criado para purificar o rebanho católico das impurezas heréticas, o Santo Ofício foi uma instituição de disciplinarização de corpos e almas segundo os ideais correntes de gênero, estamento, religião e raça; o que fazia coagindo aos que caíam em suas redes a tecerem longas confissões de si, de todos seus atos e pensamentos que podiam estar em violação das leis da Igreja. 
A ação disciplinadora do Santo Ofício português relaciona-se ao seu espirito contrarreformista. Ronaldo Vainfas aponta como objetivos do Tribunal do Santo Ofício conter o avanço do protestantismo (especialmente na península itálica), combater aqueles saberes eruditos que estivessem em conflito com os dogmas católicos (um ataque ao humanismo secular que florescera com o Renascimento) e reprimir práticas populares em discrepância com os ensinamentos da Igreja, notadamente as práticas de feitiçarias. No caso específico das inquisições ibéricas, o autor não deixa de destacar suas subordinações às Monarquias nacionais e sua violência anti-marranista (VAINFAS, 1989:189-190).

Tendo sido estabelecida em Portugal em 1536, a Inquisição, ao longo das décadas seguintes, consolidou sua estrutura e sua atuação no Reino. Ao final do século, o Santo Ofício, sentindo-se forte, estendeu seus tentáculos para as possessões ultramarinas portuguesas. Bruno Feitler comenta que a atuação do Santo Ofício na América portuguesa acompanhou a ocupação do território pelos portugueses - foi um fator a mais no complexo de ações e comportamentos que caracterizaram a transformação do espaço não europeu do Novo Mundo em parte do império católico português. O historiador contextualiza a realização da visitação de 1591 com a consolidação de núcleos populacionais de crescente importância na colônia, o que justificou a utilização, pela Inquisição, do instrumento da visitação (FEITLER, 2013:29-45).

A vinda do inquisidor D. Heitor Furtado de Mendonça ao norte da América portuguesa, ao mesmo tempo em que é tributária dos processos citados, relaciona-se também a uma mudança na política da Inquisição e da Coroa ibérica - pois se trata do período da União Ibérica, iniciada em 1580 - em relação à vigilância sobre as consciências dos súditos no ultramar. Até então, em relação à América Portuguesa, a Inquisição fizera-se presente apenas de forma indireta e esporádica, principalmente por meio do bispo da Bahia (cujo bispado fora criado em 1551) que detinha poderes inquisitoriais para efetuar prisões e instruir processos, que deveriam ser remetidos a Lisboa. Ao final do século XVI, a Inquisição buscou atuar de forma mais firme no ultramar Atlântico, comissionando visitações não só ao norte açucareiro da América portuguesa, mas também aos Açores e a Madeira (com o visitador Jerônimo Teixeira), também em 1591, e a Angola em 1596, com o padre Jorge Pereira. Comentando as razões que levaram o Tribunal da Inquisição a realizar as visitações à América portuguesa, Feitler explica que a primeira delas (liderada pelo visitador Heitor Furtado de Mendonça) se liga ao contexto de expansão geral do Santo Ofício pelas possessões atlânticas de Portugal, sendo simultânea a visitações às ilhas e à costa da África (FEITLER, 2013:32). 
Em meio às visitações enviadas à América portuguesa entre o final do século XVI e a década de 1630 (a visitação tardia ao Grão-Pará no século XVIII relaciona-se a um contexto político e religioso específico), somente a primeira (que é a que nos interessa mais de perto nesse artigo), segundo Bruno Feitler, pode ser comparada a um tribunal itinerante. Tendo contado com instrução de processos, cerimônias de leitura de sentenças e execução de penas, possuiu alcance e efeito mais profundo que as visitações posteriores. As demais visitações do período, como a segunda visitação à Bahia, entre 1618 e 1620, e a pouco conclusiva visitação às capitanias do sul (1627-1628), bem como o projeto de nova visitação à Pernambuco e à Paraíba, podem ser relacionadas à vontade de repressão mais forte ao criptojudaísmo e ao temor de uma aliança entre cristãos-novos (estigmatizados como traidores da Coroa) e os holandeses (FEITLER, 2013:29-32).

Feitas as considerações iniciais, passo à análise do problema, que será feita em quatro etapas. Inicialmente, interpretarei a confissão feita pelo padre Frutuoso Álvares ao visitador Heitor Furtado de Mendonça em busca de sinais de como suas experiências homoeróticas interagiam com suas práticas de masculinidade. Em seguida, abordarei brevemente o debate teórico em relação à condição do homoerotismo na Idade Moderna. Na terceira etapa, traçarei uma rápida genealogia da sodomia na cultura cristã, procurando entrever os significados atribuídos a ela pelo padre Frutuoso e pelo visitador. Concluirei a análise com o desdobramento do processo contra o vigário, traçando conclusões sobre uma possível convivência de masculinidade e homoerotismo.

Quando o visitador do Santo Ofício Heitor Furtado de Mendonça aportou, adoentado, na cidade do Salvador da Bahia a 9 de julho de 1591, o padre Frutuoso Álvares, natural de Braga em Portugal, um homem já velho, contando 65 anos e com barbas brancas (ANTT/IL Proc.5846: 13), logo se apresentou à Inquisição para confessar seus pecados. Portando um aspecto senhorial, à primeira vista, condizente com o ideal patriarcal que governava a masculinidade enquanto gênero performativo, o padre foi o primeiro a se confessar a Heitor Furtado no período da graça concedido a Salvador. ${ }^{2}$ Todavia, qualquer impressão que o semblante de Frutuoso Álvares possa ter causado no visitador, provavelmente foi logo desfeita pelo teor de sua confissão. ${ }^{3}$

\footnotetext{
${ }^{2}$ O tempo da graça correspondia ao período concedido pelo visitador aos fiéis para que fizessem ampla e completa confusão de seus pecados concernentes à Inquisição para salvação de suas almas e fossem perdoados, ou seja, não seriam processados pelo Santo Ofício. A graça do Santo Ofício era, porém, traiçoeira, pois o perdão estava reservado apenas àqueles que o visitador considerasse que realizassem confissão total. Assim, caso fossem denunciados por alguma falta que não fora confessada previamente, o benefício da graça perderia efeito. ". VAINFAS, Ronaldo. (Org.). Confissões da Bahia. P.26-27.

${ }^{3}$ Segundo Jean-Marie Le Gall, a Igreja tridentina, na Europa, estabeleceu regras criteriosas sobre como os padres deveriam manter sua aparência - atentando especialmente para a proibição do uso de barba, bigode e peruca e para a manutenção da tonsura. Para a Igreja, os padres deveriam manter-se barbeados e conservar a tonsura,
} 
Em sua confissão, o padre Frutuoso Álvares narrou ao talvez pasmo visitador sua vida de encontros eróticos ilícitos com "muitos moços e mancebos que não conhece nem sabe os nomes" (VAINFAS, 1997:47). Nestes encontros, o padre trocava abraços, beijos, tocamentos diversos nos sexos dos parceiros e praticava o sexo anal tanto penetrando, quanto sendo penetrado - ainda que tenha alegado, em uma aparente contradição interna a sua primeira confissão, que nunca efetuou o pecado da sodomia penetrando (VAINFAS, 1997: 47-48). ${ }^{4}$ Seus parceiros parecem ter sido sempre jovens adolescentes de idade entre 12 e 18 anos, ${ }^{5}$ a quem Frutuoso Álvares atraía para a prática do nefando (o que não significa uma posição passiva destes jovens em relação aos desejos seus e do padre, porém, as fontes, que foram escritas a partir do ponto de vista do sacerdote, não permitem uma problematização aprofundada das motivações dos parceiros sexuais de Frutuoso Álvares) usando de vários subterfúgios, mas principalmente sua posição a princípio insuspeita de velho vigário de Matoim e amigo das famílias dos jovens.

Como vigário da paróquia de Matoim, Frutuoso Álvares estava bem inserido na comunidade, conhecendo muitas pessoas e sendo por elas conhecido - o que já lhe causara problemas, como será visto abaixo. Conhecia, por exemplo, Pero d'Aguiar, morador em sua freguesia e pai de Cristóvão de Aguiar, mancebo que tinha 18 anos em 1591. Dois ou três anos antes, segundo relato do padre, ele o jovem tiveram tocamentos desonestos, abraçaramse e beijaram-se, tendo polução. Como padre, Frutuoso Álvares também conhecia, ainda que superficialmente, ao mercador fuão Siqueira, cujo sobrinho e criado, um moço chamado Antônio, teve seu pênis tocado pelo réu e confessante, carícia que não resultou em ejaculação de nenhuma das partes (VAINFAS, 1997: 46).

como modo de se distinguirem dos leigos. Por outro lado, estas mesmas práticas dos padres católicos eram criticadas pelos sacerdotes das religiões reformadas, que as apontavam como sinal da efiminação dos católicos. Em se tratando dos clérigos católicos das regiões coloniais no período, o autor faz a ressalva de que muitos não seguiam a proibição da Igreja, cultivando suas barbas - a exemplo do padre Frutuoso Álvares. LE GALL, JeanMarie. A virilidade dos clérigos. In: CORBIN, Alain; COURTINE, Jean-Jacques; VIGARELLO, Georges. (Orgs.). História da virilidade 1. A invenção da virilidade da Antiguidade às Luzes. Petrópilis, RJ: Editora Vozes, 2013, p. 246-247.

${ }^{4}$ Esta contradição presente na primeira confissão do padre Frutuoso Álvares ao visitador pode ser interpretada pelo historiador como uma possível estratégia defensiva retórica implementada pelo réu para tentar evitar a culpa mais grave de sodomia perfeita (penetração anal com ejaculação interna). Ao mesmo tempo, o intérprete moderno do depoimento do padre precisa ter em mente o quão extenuante e amedrontadora era a situação de depor à Inquisição, o que podia muito bem resultar em depoimentos contraditórios e confusos - fosse ou não de maneira intencional pelo réu. Confissões da Bahia. P.47-48.

${ }^{5}$ Em sua longa confissão, o padre Frutuoso citou vários parceiros de suas práticas sodomíticas. Mesmo não sendo mais capaz de dizer o nome de todos (talvez de alguns ele nunca o soube?), outros ele pode nomear, sendo um deles Gerônimo, estudante em Salvador, irmão do cônego Manuel Viegas e que tinha 12 ou 13 anos quando praticou o nefando com o réu. Confissões da Bahia. P.48.

\section{Filistorias}


Sendo um homem de práticas sodomíticas notórias, ${ }^{6}$ Frutuoso Álvares mesmo assim conseguiu, ao longo dos vários anos em que exerceu o ofício de vigário na comunidade de Matoim, cultivar amizades duradouras com os pais ou senhores de seus parceiros eróticos. Tal fato põem em questão a performance de gênero encenada cotidianamente pelo réu. Teriam homens ciosos de sua virilidade - como eram os homens da América portuguesa no período estreitado amizade, recebendo em sua casa e permitindo que seus dependentes frequentassem a casa do padre, se a apresentação pública do mesmo - se sua performatividade de gênero não se conformasse ao ideal hegemônico de masculinidade corrente?

Tendo em vista o pesado estigma social associado ao feminino (matriz do pecado na tradição cristã), percebe-se que a identidade de gênero do padre Frutuoso Álvares, não obstante suas práticas homoeróticas, pautava-se pelos padrões culturalmente estabelecidos para a masculinidade. Por sua posição de vigário da paróquia do Matoim, o padre exercia funções de patriarca espiritual da comunidade, papel reforçado por sua idade avançada e aparência física. Como tal, foi capaz de articular uma rede de sociabilidade masculina que lhe angariava vantagens explícitas - como usar da hospitalidade dos amigos homens - e implícitas - ganhar a confiança de adolescentes e atraí-los para os prazeres nefandos.

Se os prazeres carnais com rapazes não parecem informar a composição da identidade de gênero do padre Frutuoso, que lugar ocupavam tais práticas em sua visão de mundo? Nas suas palavras - conforme traduzidas pelo notário a mando do visitador: “(...) sabia muito bem quão grandes pecados sejam estes que tem cometido, e deles está muito arrependido e pede perdão" (VAINFAS, 1997: 49). Suas experiências eróticas com jovens, o padre Frutuoso Álvares as traduzia como ações pecaminosas, as quais, devido à fraqueza da Carne, ele não deixava de cometer a despeito das sucessivas sanções sofridas ao longo da vida.

À interrogação de em que medida as práticas sodomíticas e de masculinidade do padre Frutuoso compunham sua identidade, subjaz a polêmica sobre a relação entre sodomia e homossexualidade. Era o sodomita homossexual de algum modo semelhante ao que entendemos hoje? Ou era um pecador que ofendia a Deus com seus graves atos contra a natureza? Analisarei a seguir os principais pontos dessa discussão travada por duas linhas de pensamento acerca da sexualidade.

\footnotetext{
${ }^{6}$ Além dos processos que sofrera ao longo de sua vida em Braga, Cabo Verde e Lisboa, o padre Frutuoso Álvares fora processado pelo ordinário do bispado da Bahia em pelo menos duas oportunidades, pelo ajuntamento carnal que mantivera com Diogo Martins (investigação que não logrou condená-lo) e por trocar tocamentos desonestos com os irmãos Antônio Álvares e Manuel Álvares - desta feita, a investigação, fundamentada em testemunhos de cinco pessoas, resultou em sua condenação com multa e suspensão das ordens por certo tempo. Segundo o relato do padre, a investigação mais recente fora realizada na visitação feita pelo provisor do bispo no ano de 1590, um antes da chegada da Inquisição à Bahia. Confissões da Bahia. P.48, 50-51.
} 
Essa polêmica diz respeito ao debate acadêmico transdicisplinar travado entre duas correntes de pensamento com visões antagônicas a respeito da sexualidade e das identidades de gênero. Trata-se do debate entre as correntes essencialista e construcionista, que divergem sobre a historicidade das identidades sexuais e de gênero como as de sodomita e de homossexual.

De acordo com a interpretação essencialista da dimensão sexual da experiência humana, existem essências humanas universais ou naturais subjacentes a qualquer análise das expressões sexuais de qualquer cultura em diferentes tempos e espaços, identidades que seriam dadas pela natureza (BARBO, 2008: 22). Para a corrente essencialista, a homossexualidade é um dado exterior à sua delimitação discursiva; o marco apresentado por Foucault como seu começo nas sociedades industriais não seria mais do que uma nova nomeação a elementos que já existiam mesmo antes de serem nomeados (GARCIA, 2007: 33 34). Importante autor desta corrente de pensamento é o historiador estadunidense John Boswell, cujo livro Christianity, social tolerance and homosexuality (em que ele defende a equivalência entre sodomia e homossexualidade, postulando a possibilidade do uso e circulação do termo gay no idioma catalão-provençal para praticantes do sexo homoerótico desde o século XIII) (BOSWELL, 1980: 43), cuja obra foi constantemente citada por historiadores brasileiros entre a década de 1980 e 1990 para legitimar a igualdade entre sodomitas dos séculos XVI ao XVIII e homossexuais do século XX.

Em seu texto, Boswell pretendeu desvendar as raízes culturais da intolerância devotada a alguns grupos cujas práticas eróticas desviavam da moral hegemônica. Intolerância que, usando de argumentos religiosos (cristãos), não se focava com a mesma intensidade em todos os grupos condenados pelas escrituras sagradas do cristianismo. Neste sentido, o autor comenta os diversos tratamentos dados pelos Estados cristãos da Época Moderna às prostitutas e aos sodomitas (aos quais ele sempre se refere como gays) - os dois grupos condenados com veemência semelhante pela Bíblia. Porém, para atingir este objetivo, o historiador postula a universalidade da experiência homoerótica na história, aproximando as experiências gays do século XX com aquelas dos gais da região da Catalunha e da Provença entre a Baixa Idade Média e a Modernidade. Este movimento teórico justificar-se-ia, no entender de Boswell, pela circulação (que ele próprio reconhece como controversa e cuja história é lacunar e duvidosa) do termo gai (que poderia se referir a poesia, a amantes em geral e a amantes homoeróticos) desde o sul da França entre os séculos XIII e XIV e a Inglaterra e os Estados Unidos no século XX (BOSWELL, 1980: 3-43, nota 6). 
O antropólogo, historiador e decano do moderno movimento gay no Brasil, Luiz Mott é talvez um dos maiores estudiosos da questão da sodomia no mundo luso-brasileiro na Época Moderna, tendo pesquisado exaustivamente os documentos inquisitoriais na Torre do Tombo em Lisboa. Defensor da perspectiva essencialista, o historiador e antropólogo usou em vários textos o estudo de Boswell como justificativa para o uso do termo gay como epíteto válido para se referir a sodomitas entre os séculos XVI e XVIII (MOTT, 1988a: 42, nota 6).

Em seus muitos textos sobre a sodomia e os sodomitas, publicados desde a década de 1980, o autor emprega variados termos para se referir aos homens com práticas homoeróticas; tais como uranistas, pederastas, homófilos, terceiro sexo, nefandistas, ganimedes (para sodomitas mais jovens e efeminados), vício de Veneza ou vício italiano, amor socrático ou amor grego, amor sáfico, vício dos clérigos e amor que não ousa dizer seu nome. Vários destes cognomes demonstram o que Daniel Barbo considerou como sendo o forte peso dos estudos da cultura grega clássica durante o período de gestação da moderna categoria da homossexualidade, como os amores socrático e sáfico, uranistas e ganimedes (BARBO, 2013: 11-42).

Duas críticas podem ser feitas à corrente essencialista. Em primeiro lugar, por tomar como pressuposto a existência de uma essência trans-histórica para as identidades de gênero e sexuais, ela tece uma história marcada pela linearidade e pela teleologia. Em várias passagens, Luiz Mott explicita seu interesse em construir uma história para os homossexuais, articulando (como fundamentalmente semelhantes) dispositivos distintos de repressão ao homoerotismo. ${ }^{7}$

Uma história articulada deste modo corre o risco de gerar simplificações e anacronismos, pois as experiências de gays do século XX e de sodomitas dos séculos XVI ao XVIII guardam significativas diferenças - a começar pelos termos com que cada grupo significava suas práticas homoeróticas; os primeiros como condição mais fundamental de sua identidade de sujeitos humanos, os segundos como pesado e prazeroso pecado da Carne.

A segunda crítica refere-se à construção de mitos engendrada pela essencialização da história da homossexualidade. Uma vez que a homossexualidade é um dado natural que atravessa épocas, culturas e continentes, recebendo diversos nomes, mas conservando uma essência imutável, aqueles que praticaram o homoerotismo no passado (e foram por isso

\footnotetext{
${ }^{7}$ Luiz Mott, por exemplo, comparou a perseguição inquisitorial aos sodomitas ao extermínio de homossexuais pelo nazismo. MOTT, Luiz. O sexo proibido. Virgens, gays e escravos nas garras da Inquisição, Campinas, SP, Papirus, 1988. P.114-115.
} 
perseguidos, muitos executados) surgem como heróis e mártires da história e da causa homossexual. ${ }^{8} \mathrm{O}$ antropólogo Luiz Mott, por exemplo, é explícito em sua intenção política:

\begin{abstract}
Alguns, modelos e paradigmas na luta contra o racismo, contra a intolerância inquisitorial, contestadores do machismo, os mesmos defeitos de nossa civilização judaico-cristã que ainda hoje causam a desgraça das minorias oprimidas. Que estes ilustres desconhecidos - agora identificados - também tenham o direito à história. E os oprimidos, seus heróis (MOTT, 1988a: 9).
\end{abstract}

A crítica ao essencialismo não significa desprezar as contribuições historiográficas dos seus autores - apenas pô-las em relação aos significados específicos das identidades sexuais e de gênero em questão, no caso, as dos sodomitas. Essa ressalva é de particular importância em relação ao artigo Pagode português: A subcultura gay em Portugal nos tempos inquisitoriais de Luiz Mott. Neste texto, o autor tece o panorama de uma Lisboa dos tempos inquisitoriais insuspeita, em que o homoerotismo dos sodomitas se desenvolveu em códigos culturais próprios e dedicados a permitir a continuidade de suas práticas nefandas mesmo contra os próprios muros da Inquisição - como nas portas de Santo Antônio e nos Arcos do Rocio, na vizinhança das instalações do Santo Ofício em Lisboa. Entre lugares públicos e estalagens para encontros efêmeros, casas particulares que serviam de ponto de reunião para círculos de amigos que tinham em comum experiências performativamente subversivas de gênero (sodomitas efeminados que enfatizavam em suas vestes, falas e gestos essa característica), vocabulário específico a estes grupos e mesmo sodomitas intelectualizados capazes de se apropriarem dos discursos condenatórios da sodomia para construir uma positividade para esta prática sexual, a cultura portuguesa dos séculos XVII e XVIII ganha novos traços que atestam a força de incitação à discursificação do sexo era capaz, já na Época Moderna, de engendrar pontos de resistência expressivos da capacidade de estilização da existência mesmo de sodomitas ameaçados sempre pelo espectro da fogueira inquisitorial (MOTT, 1988c, 127137).

É também neste texto que Luiz Mott torna mais evidente seu alinhamento à corrente essencialista, apresentando um desafio ao construcionismo em geral e a teoria de Michel Foucault em particular. A sofisticação dos códigos comunicativos dos sodomitas em Portugal

\footnotetext{
${ }^{8}$ Não se trata aqui de criticar-se o entrelaçamento da política e da militância com a historiografia. Conforme demonstrou Joan Scott, a oposição entre teoria e política é falsa e produtora de violências, pois silencia debates necessários acerca de qual teoria pode apresentar maior utilidade para determinada política, fazendo com que, em um movimento excludente, uma única teoria seja alçada ao posto de aceitável como política. Assim, não se critica a militância do historiador, apenas possíveis anacronismos que dela podem derivar sem a correlata reflexão teórica a respeito dos conceitos importados da práxis política. SCOTT, Joan. História das Mulheres. In: BURKE, Peter (org.). A escrita da história: novas perspectivas. São Paulo: Ed. UNESP, 1992. P.87-98.
} 
entre os séculos XVII e XVIII (interpretados pelo autor como uma subcultura gay não muito diversa daquela existente nas grandes cidades ocidentais durante o século XX) levou-o a concluir pela existência de uma condição homossexual única através dos séculos, colocando em xeque a proposição de Foucault de que a homossexualidade seria uma invenção do dispositivo da sexualidade nas décadas finais do século XIX(MOTT, 1988c, 137-138).

Diferentemente de Luiz Mott, o historiador Ronaldo Vainfas não rejeita tão peremptoriamente a opção construcionista, na medida em que a teoria do incitamento à discursificação do sexo (e o modelo de poder a ela subjacente) conforma a interpretação do funcionamento do Tribunal do Santo Ofício em sua perseguição aos delitos morais. A incerteza sobre o estatuto da sodomia era, segundo um autor, uma dúvida compartilhada entre os eruditos representantes dos poderes persecutórios e os sodomitas que a praticavam. Mais além, é uma dúvida que também alimenta as pesquisas de estudiosos contemporâneos da questão (VAINFAS, 1989: 50;143-144).

Ronaldo Vainfas leva em consideração a posição construcionista acerca da homossexualidade logo no início do capítulo quinto do seu Trópico dos Pecados, em que analisa as condições de existência do pecado nefando, e seus praticantes, na América portuguesa. Todavia, a ideia foucaultiana de que a sodomia seria antes de tudo um conjunto de atos que não caracterizam a cerne da identidade dos sujeitos é logo posta de lado pelo historiador (VAINFAS, 1989:144).

Para o autor, o ambíguo conceito de sodomia desenvolvido pelo saber escolástico e pelas percepções populares desde a Alta Idade Média invalida a tese de que a sodomia não foi mais do que um conjunto de atos pecaminosos e criminais praticados por algumas pessoas. No entanto, ainda que a sodomia não se resumisse a certos atos eróticos proibidos (mais ou menos graves se praticados com determinados parceiros) e envolvesse também comportamentos de gênero diversos que pudessem estar em desacordo com os padrões esperados de masculinidade e feminilidade, a hipótese de Foucault não ficaria invalidada. A diferença profunda entre homossexualidade e sodomia persiste, qual seja, de que a prática homoerótica experimentada por inúmeros homens e mulheres, antes do final do século XIX, não era percebida, sentida e experimentada como a verdade mais interna da identidade daqueles indivíduos como sujeitos.

Michel Foucault aborda a questão da historicidade da homossexualidade a partir de sua análise dos mecanismos de funcionamento do dispositivo da sexualidade, postos em funcionamento a partir do século XVIII nas sociedades europeias em que o capitalismo se desenvolveu primeiro e mais fortemente. A sexualidade, para o autor, e, de modo correlato, a 
homossexualidade, não se destaca do sistema capitalista. A implementação perversa da sexualidade, ao longo do século XIX, se deu por meio de quatro operações das relações de poder, que alimentam uma a outra de modo contínuo e dinâmico, estando presentes ainda hoje nas sociedades ocidentais. A que mais de perto concerne à história da homossexualidade é a segunda operação, denominada especificação nova dos indivíduos (FOUCAULT, 1977:41 $55)$.

Esta operação do poder funcionou pela incorporação, progressivamente mais profunda, das práticas sexuais periféricas aos indivíduos, ao ponto de tornarem-se a parte mais essencial da sua identidade. Práticas sexuais que até então não foram mais do que isso (práticas, atos) passaram a compor e a determinar a história, a morfologia, a anatomia, a fisiologia de indivíduos que, a partir de então se transformaram em personagens de si mesmos. A função deste mecanismo é produzir objetos sobre os quais o poder pode exercer-se, criando, e disciplinando, corpos que justificam sua mera existência. Esta operação é, pois, um mecanismo de classificação dos indivíduos, transformados em novos personagens (perversos), uma nova realidade analítica, visível e permanente, semeando-a no real e incorporando-a nos indivíduos (FOUCAULT, 1977: 46-48).

A categoria da homossexualidade é usada por Foucault como exemplar do funcionamento desta operação das relações de poder dentro do dispositivo da sexualidade. $\mathrm{O}$ homossexual passou a ser visto como aquela pessoa que apresentasse algo como um hermafroditismo da alma, em que a mentalidade e corpo tinham gêneros divergentes. Qualidade que o marcaria por inteiro em todas as suas ações, em toda a sua história de vida, em todos os seus gestos e palavras. Foucault diferencia o homossexual do sodomita argumentando que este era apenas um homem que cometia certos atos pecaminosos (gravíssimos, mas que não diziam da sua natureza como um todo), enquanto o homossexual era definido enquanto sujeito prioritariamente por suas experiências (homo)eróticas (FOUCAULT, 1977: 47).

Ao deslocar a categoria homossexual para a posição de efeito discursivo das relações de poder, e não um dado da natureza a que o poder dedicar-se-ia infinitamente a reprimir, o filósofo o francês abriu espaço para que contra-discursos sobre a categoria pudessem ser analisados dentro dos próprios mecanismos da sexualidade, abordando esse dispositivo como uma dimensão da natureza proliferativa do poder - suas teorias sobre o funcionamento do dispositivo da sexualidade compõem sua famosa crítica à hipótese repressiva da sexualidade. Para ele, as sociedades ocidentais industriais e burguesas não se caracterizam por uma repressão sempre maior do sexo; ao contrário, são marcadas por um falar incessante deste 
sexo, que passou a compor a chave das identidades de todos os indivíduos nestas sociedades (FOUCAULT, 1977: 19-53).

A corrente construcionista segue de perto a narrativa foucaultiana, trabalhando a partir da ideia de que a homossexualidade é mesmo uma invenção do século XIX burguês e industrial. Segundo David Halperin, os processos que levaram ao surgimento da sexualidade foram dois. Um foi a separação do domínio sexual na vida dos indivíduos dos outros domínios culturais (como a religião, a moral e o direito) a que estava ligado antes, e sua conseguinte definição como um aspecto específico da natureza psicofísica dos indivíduos. $\mathrm{O}$ segundo processo foi a construção da ideia de que há uma essência interior do sexo dos indivíduos, a construção da ilusão da interioridade do sexo, que seria a raiz das identidades (performativas) de todos e de todas (HALPERIN, 1980). Deste ponto de vista, a corrente essencialista seria uma reiteração do mecanismo de poder de criação de identidades sexuais estáveis ao longo da história - cujo funcionamento autônomo seria natural, portanto dispensando intervenções políticas ou teóricas sobre as violências que engendram.

Tendo em vista o complexo debate entre estas duas correntes, um nível de prudência na utilização das categorias homossexual e homossexualidade em contextos diversos do mundo Ocidental a partir do fim do século XIX é recomendável. Por essa razão, o termo homoerotismo ganha relevo na abordagem de comportamentos eróticos entre pessoas do mesmo sexo em diferentes momentos no tempo e no espaço. De acordo com psicanalista Jurandir Freire Costa, o emprego dos termos homossexual e homossexualidade oferece insegurança teórica, uma vez que remete ao vocabulário do século XIX. O termo homoerotismo, por outro lado, contorna este ponto enfraquecedor da análise por ser mais flexível e não estar desde já carregada pelos investimentos de poder e pelos preconceitos sociais que saturam a categoria de homossexualidade. O homoerotismo é uma categoria cuja flexibilidade é mais adequada para descrever a pluralidade das práticas e desejos de pessoas por outras do mesmo sexo. Ele afasta também as referências a patologização destas práticas subjacente à categoria homossexualidade em seu contexto original de produção. O termo homoerotismo mantém a possibilidade dos sujeitos se relacionarem sexualmente de diversas maneiras com pessoas de seu sexo ou não (COSTA, 1992: 13-40).

O sociólogo argentino Carlo Figari igualmente defende o uso da categoria homoerotismo no estudo de prazeres e relações eróticas entre pessoas do mesmo sexo em sociedades que não o Ocidente ao fim do século XIX. Partindo também do ponto de vista construcionista, o autor propõe que o homoerotismo funcione como um elo significante entre os comportamentos eróticos envolvendo homens e mulheres entre si no passado e o aparato da 
heterossexualidade compulsória que orienta, no presente, a pesquisa a ser feita. Assim, a categoria, desprovida de significados, tem espaço para a interpretação de fenômenos em pontos diferentes no tempo e no espaço e que dizem respeito a práticas que, com sentidos muito diversos, coexistem no passado histórico e no presente do analista - como o amor e o prazer entre homens e entre mulheres (FIGARI, 2007: 19). Nesse deslocamento da categoria da homossexualidade na Época Moderna, desloca-se também, implicitamente, a heterossexualidade compulsória no presente.

Estabelecidos os pontos de vista divergentes em relação ao estatuto sexual e de gênero da sodomia, há que se atentar também para o caráter ambíguo do conceito na tradição cristã desde o início do cristianismo até a Época Moderna. Esta não é uma discussão fácil ou encerrada. Ao contrário, desde os primórdios do cristianismo, o conceito de sodomia sofreu inúmeras transformações e, hoje, seu caráter mutante enseja discussões historiográficas a respeito de seu estatuto em relação ao conceito de heresia e à ação inquisitorial.

O termo refere-se originalmente ao episódio bíblico da destruição da cidade de Sodoma pela ação da ira divina contra seus habitantes. Os primeiros teólogos da Patrística e, especialmente, São Paulo assimilaram a condenação divina ao comportamento homoerótico dos habitantes em relação aos anjos hóspedes de Lot. ${ }^{9}$ Boswell argumenta que essa interpretação prevaleceu sobre outra que considerava a ofensa dos sodomitas aos anjos apenas como quebra das regras de hospitalidade - importantes na tradição hebraica (BOSWELL, 1980: 96-97).

Até a Baixa Idade Média, o conceito teológico de sodomia careceu de definição estrita. Era apenas mais um no vasto rol de práticas sexuais condenadas pela Igreja - que, a rigor, só permitia, e mesmo assim, com alguma dificuldade antes dos séculos XI e XII, o sexo entre cônjuges com vistas à reprodução. A sodomia confundia-se então com os conceitos mais amplos de luxúria e fornicação - ainda que a abjeção ao sexo anal tivesse destaque na tradição católica, sendo este o ato sodomítico principal (VAINFAS, 1989: 145).

A partir dos séculos XI e XII, a sodomia começou um movimento de ascensão na escala de gravidade dos pecados organizada pelos sábios da escolástica. Sua definição, ainda incerta, envolvia então todos os atos de desvio da genitalidade no sexo tanto entre parceiros iguais como em diferentes - e o sexo anal continuava sendo sua forma mais detestável. Entre

\footnotetext{
${ }^{9}$ As condenações de S. Paulo ao homoerotismo encontram-se em suas epístolas, como em Romanos 1:24-31, I Coríntios 6:9-10 e I Timóteo 1: 10. Bíblia Sagrada. Rio de Janeiro: Catholic Press, 1967. (Barsa).
} 
os séculos XIII e XIV, assume a posição de pecado mais grave, confundindo-se muitas vezes com o pecado da bestialidade - o copular com animais (VAINFAS, 1989: 145-146).

Deste período até o século XVIII, os significados da sodomia oscilaram, nos saberes teológicos, entre uma definição centrada na morfologia do ato (a cópula anal com ejaculação interna) ou no homoerotismo (sendo mais perfeita a relação entre homens e entre mulheres). São Tomás de Aquino a considerou uma dos quatro clamantia peccata (pecados que clamam ao céu), definindo-a como a cópula entre pessoas do mesmo sexo e considerando o sexo anal entre dois homens com ejaculação interior sua forma mais perfeita - logo mais grave (VAINFAS, 1989: 146-147).

Luiz Mott argumenta que debalde as mudanças sofridas pelo conceito de sodomia ao longo da Era Cristã, ele jamais foi identificado como heresia. Para o autor, a perseguição aos sodomitas empreendida pelo Tribunal do Santo Ofício na modernidade foi, mais que um combate a uma seita herética, uma tática de repressão à ameaça ao patriarcado, aos valores da família, da superioridade masculina e à autoridade da Igreja, representada pelo grupo - cujos membros seriam portadores de uma contracultura imoral e revolucionária (MOTT, 2006: 253266). Com isso concorda obliquamente Ronaldo Vainfas, que considera ter sido o movimento teórico empreendido por alguns tribunais do Santo Ofício para legitimar sua jurisdição sobre a sodomia mais sutil do que a simples identificação entre sodomia e heresia (VAINFAS, 2006: 267-280).

Diante da oscilação constatada pelo autor na definição de sodomia pelos saberes eruditos, Ronaldo Vainfas enfatiza que os inquisidores tinham mais dúvidas do que ninguém acerca deste pecado - tendo certeza apenas sobre sua enorme gravidade, que o tornava nefando, do qual não se deveria sequer falar. O historiador entende que sodomia e heresia não foram identificadas, mas assimiladas, isto é, deveriam ser tratadas de modo semelhante no cotidiano dos tribunais. A inclusão da sodomia na jurisdição inquisitorial (que, no caso português, ocorreu em 1553, por provisão do rei Dom João III, reforçada em sequência por provisão do Cardeal e inquisidor-geral D. Henrique em 1555$)^{10}$ fez parte de um processo mais amplo de consolidação e expansão do Santo Ofício em Portugal. Para tanto, a Inquisição operou a transformação, algo arbitrária, de vários pecados em divergências em matérias de fé que poderiam esconder doutrinas heréticas. No caso da sodomia, as dúvidas sobre o caráter

\footnotetext{
${ }^{10}$ A passagem da sodomia (em suas diversas formas) para a jurisdição do Santo Ofício português foi gradual. A sodomia não constava na lista de crimes que originalmente a Inquisição deveria perseguir em Portugal de acordo com o primeiro monitório publicado no momento de sua fundação em 1536. Apenas na década de 1550, provisões régias (1553 e 1555) dispuseram do tema na arena inquisitorial. As provisões foram sancionadas por Breves Apostólicos da Santa Sé nas décadas seguintes (por Pio IV em 1562 e por Gregório III em 1572). O regimento inquisitorial de 1613 incorporou esses dispositivos jurídicos, estabelecendo a sodomia de forma definitiva entre os crimes de alçada do Santo Ofício. BELLINI, Lígia. A coisa obscura. P.86-87.
} 
herético ou não dos pecadores eram somadas às dúvidas sobre o que constituía o pecado em si, uma vez que a ambiguidade do termo (entre a condenação ao sexo anal ou ao homoerotismo) não fora tampouco sanada (VAINFAS, 2006: 269-279).

Destarte, no momento da vinda do visitador Heitor Furtado de Mendonça à América Portuguesa, o Santo Ofício tinha mais dúvidas do que certezas em se tratando da sodomia. Embora sua forma mais perfeita, grave e abjeta fosse a penetração anal entre dois homens com ejaculação interna, ela também envolvia, de um lado, a cópula anal entre homem e mulher, a sodomia dita imperfeita, e o sexo entre duas mulheres, chamada sodomia foeminarum. ${ }^{11}$ De fato, Heitor Furtado ouviu denúncias, confissões e instaurou processos contra réus das três modalidades de sodomia.

Neste contexto, torna-se difícil julgar que alguém como padre Frutuoso Álvares pudesse ter construído para si uma identidade centrada nos furtivos encontros homoeróticos que manteve, ao longo de várias décadas, com inúmeros rapazes. Se o conceito de sodomia era impreciso para os eruditos inquisidores, para o entendimento popular, não o era menos. ${ }^{12}$ Se para os moralistas herdeiros da tradição escolástica a cópula anal era a marca maior da sodomia, para as pessoas comuns, os sodomitas eram identificados principalmente por assumirem comportamentos atribuídos mais frequentemente às mulheres. Ou seja, na cultura popular, a sodomia era caracterizada pela inversão performativa das marcas de gênero, confundindo a masculinidade e a feminilidade, desestabilizando-nas. Todavia, os contatos entre a cultura popular e a tradição escolástica - promovidos pela própria Inquisição por meio

\footnotetext{
${ }^{11}$ Ainda que o relacionamento sexual entre duas mulheres tenha sido enquadrado pela Inquisição como uma forma de sodomia, os inquisidores portugueses tiveram, de acordo com Ligia Bellini, muitas dúvidas a respeito não só do modo como deveriam processar as rés acusadas de sodomia feminina, mas mesmo se elas deveriam ser processadas pela Inquisição. Tal dúvida era derivada da ambiguidade do conceito de sodomia, cujos múltiplos significados tendiam a privilegiar as características do coito entre homem e mulher, e a se centrar no desperdício do sêmen, o que ocorre especialmente no coito pelo vaso traseiro, e a desvalorizar práticas corporais alternativas, que não tivessem o aparelho sexual masculino como centro - emulando um modelo falocêntrico de cópula sexual. Assim, o Conselho Geral da Inquisição decidiu, entre 1644 e 1646, após consulta feita pelo Tribunal de Goa, que o Santo Ofício não deveria tomar conhecimento destes crimes até nova ordem. Isto não impediu que dispositivos contra a sodomia feminina fossem repetidos em regimentos posteriores, como no de 1774, demonstrando a indecisão do Santo Ofício no que diz respeito ao assunto. Ademais, a historiadora pondera que nem sempre é claro quando essa legislação se refere à sodomia imperfeita (sexo anal) entre homem e mulher ou ao pecado nefando entre duas mulheres. BELLINI, Ligia. A Coisa Obscura. Mulher, sodomia e inquisição no Brasil Colonial. São Paulo: Brasiliense, 1989, p. 51-70.

${ }^{12} \mathrm{O}$ padre Frutuoso era originário de uma família humilde e de oficiais mecânicos. Seu pai João Álvares fora pichaleiro, assim como seu irmão Tristão Gonçalves. Seu avô paterno fora lavrador e seus avós maternos Sebastião Gonçalves e Catarina, estalajadeiros. Dois tios maternos também eram oficiais mecânicos, Antônio Gonçalves era rendeiro e Giraldo Gonçalves, livreiro. A autora comenta que, apesar do defeito mecânico de seu sangue (que poderia torna-lo inelegível a certos cargos na sociedade hierárquica do Antigo Regime em Portugal), o padre Frutuoso logrou uma ascensão social, pois recebeu ordens maiores e recebeu a paróquia de Matoim para ser vigário (não obstante, também seu envolvimento com a Inquisição no reino). Não se sabe, contudo, se o padre era graduado. Processo do Padre Frutuoso Álvares, PT-TT-TSO/IL/28/5846, páginas 27-28.
} 
dos autos-de-fé, das leituras públicas das sentenças e pela publicação dos éditos e dos monitórios - fizeram com que o sexo anal também fosse reconhecido popularmente como símbolo da sodomia (VAINFAS, 1989:147-151).

O padre Frutuoso Álvares fez longa confissão no período da Graça, porém, por não ter confessado todas as cópulas sodomíticas mantidas com o jovem Jerônimo Parada, foi instaurado processo contra ele pelo visitador. Jeronimo era estudante e contava 17 anos quando se apresentou, sem ser chamado, a Heitor Furtado de Mendonça para confessar suas culpas. O jovem baiano era filho de Domingos Lopez, carpinteiro de ofício, e de Lianor Viegas, todos moradores na cidade da Bahia (ANTT/IL Proc.5846:11-12).

Em sua confissão, feita a 17 de agosto de 1591, descreveu o início de seu relacionamento com o padre Frutuoso, que logo evoluiu para trocas eróticas entre eles. $\mathrm{O}$ primeiro encontro carnal entre eles se deu em um domingo de Páscoa dois ou três anos antes portanto em 1588 ou 1589 - em que Jeronimo foi à casa do padre. A razão da visita não foi dita, apenas que o sacerdote era amigo do pai e do irmão (e, como dirá a frente, de seu avô). Conversando os dois, logo o padre começou a dizer-lhe palavras meigas, elogiando-o como estava gordo (seria inadequado imaginar o jovem enrubescendo com os elogios do velho vigário?). Das palavras, o sodomítico padre passou à ação, logo procurando tocar o pênis do rapaz e tornando-o ereto ("e lle meteo/ a mã̃ pelos calções e lle apalpou a/ sua natura alvoracandollo com/ a maõ"). Estando Jeronimo neste estado, não perdeu tempo Frutuoso em levá-lo para o quarto, onde se deitaram na cama e, ajuntando suas naturas uma com a outra, masturbou-as ambas o padre. No entanto, segundo Jeronimo, desta feita nenhum deles tiveram polução - talvez por ter sido a primeira vez (ANTT/IL Proc.5846:13).

O segundo encontro dos amantes também foi na casa do padre Frutuoso, em uma ocasião em que Jeronimo precisou pernoitar em Matoim e para isso se abrigou na casa do vigário. Repetiram-se as carícias da primeira vez e novamente não houve ejaculação de nenhuma das partes (ANTT/IL Proc.5846:14). Muitos dias depois, foi a vez de Frutuoso se deslocar a cidade da Bahia, onde se hospedou na casa do avô de seu jovem amante. Quando ficaram a sós, o sacerdote logo convidou Jeronimo a fazerem como das outras vezes. Desta feita, contudo, o jovem se negou. Negativa logo contornada pelo padre através da oferta de dois vinténs. ${ }^{13}$ Vencida a resistência de Jeronimo, passaram os amantes às carícias, e, desta vez, foram além de tocamentos desonestos, pois

\footnotetext{
${ }^{13}$ Pode-se ver aqui a exploração da miséria, típica de sociedades de Antigo Regime, que Vainfas identificou como característica das relações sodomíticas. VAINFAS, Ronaldo. Inquisição como fábrica de hereges: os sodomitas foram exceção?. P.121-122.
} 
o djtto clerjgo Se deyjou cõ a barriga pe/ ra bajxo e djxe aelle cõfeSsante que/ Se pusesse Em cjma delle e aSsim o feZ/ E dormjo com o djtto clerjgo carnal/ mente por detrás conSumando o pec/cado de Sodomja metendo Seu membro/ deShonesto pello vaso traZejro do cle/ rigo Como hum homẽ faZ com huã/ moller/ moller pello vaso natural por diante/ E este peccado consumou tendo polução (ANTT/IL Proc.5846:15-16).

Estava consumado o nefando pecado da sodomia e, por força do demônio e fraqueza da Carne, consumada perfeitamente com ejaculação intra vas por parte do jovem Jeronimo da Parada.

Como foi dito, a confissão de Jeronimo da Parada dificultou a situação do padre Frutuoso Álvares perante o Santo Ofício, pois esta cópula sodomítica não foi confessada por ele no tempo da graça. Foi somente em seu segundo depoimento a Heitor Furtado de Mendonça (feita a sete de julho de 1593) que o vigário assumiu esta culpa, pedindo misericórdia ao visitador (ANTT/IL Proc.5846:23-26).

Misericordiosa de fato foi a sentença emitida pelo visitador a 21 de julho de 1593 . A sodomia era um crime gravíssimo nos regimentos da Inquisição e nas Ordenações do Reino. Era equiparado ao crime de lesa-majestade e o condenado poderia até mesmo ser relaxado ao braço secular para ser queimado vivo na fogueira. De acordo com as Ordenações Afonsinas,

Sobre todosllos peccados bem parece Seer mais torpe, çujo, e desonesto o peccado da Sodomia, e nom he achado outro tam avorrecido ante DEOS, e o mundo, (...) E Segundo diSSerom os naturaes, Soomente fallando os homees em elle Sem outro algum auto, tam grande he o Seu avorrecimento, que o aar ho nom pode Soffrer, mais naturalmente, he corrumpido, e perde sua natural virtude. E ainda Se lee, que por eSte peccado lançou DEOS o deluvio Sobre a terra, quando mando a Noé fazer huã Arca, em que eScapaSSe el, e toda Sua geeraçom, per que reformou o mundo de novo; e por eSte peccado Soverteo as Cidades de Sodoma, e Gomorra, (...); e por este peccado foi estroida a Hordem do Templo per toda a ChriStandade em hum dia. E porque Segundo a qualidade do peccado, aSSy deve gravemente Seer punido: porem Mandamos, e poemos por Ley geral, que todo homem, que tal peccado fezes, per qualquer guiSa que Seer poSSa, Seja queimado, e feito per fogo em poo, e por tal que já nunca de Seu corpo, e Sepultura poSSa Seer ouvida memoria. ${ }^{14}$

O padre Frutuoso Álvares estava, portanto, diante da fogueira quando sua sentença foi emitida - aliás, como estavam todos os sodomitas portugueses. ${ }^{15}$ No texto de sua sentença foi

14 Ordenações afonsinas, Livro V, título XVII, Dos que cometem peccado de Sodomia. Disponível em: http://www1.ci.uc.pt/ihti/proj/afonsinas/15pg53.htm. Último acesso a 28 de setembro de 2013.

${ }^{15}$ Não obstante a severa legislação repressiva, Luiz Mott argumenta que a Inquisição portuguesa foi bastante menos rigorosa com os sodomitas que suas congêneres espanholas e mesmo que tribunais civis nos reinos protestantes. Enquanto a Inquisição portuguesa, entre os séculos XVI e XVII, queimou por volta de 30 sodomitas (não tendo condenado nenhum à fogueira no século XVIII), a Inquisição de Saragoça queimou 15 sodomitas só 
recapitulada sua confissão no tempo da graça, expondo suas várias culpas e, ao mesmo tempo, sua trajetória de vida. Caso ocorresse leitura pública da sentença (o que não foi o caso), a humilhação do réu seria maior e o povo teria a oportunidade de saber quais crimes conduziram-no àquela situação de opróbio - e quais condutas deveriam ser evitadas, pois, para não ocupar futuramente o lugar de réu estigmatizado. Ainda que sua confissão na graça tenha sido considerada diminuta, o padre Frutuoso Álvares gozou da misericórdia e da complacência do visitador, no que pesaram sua idade avançada, sua condição de clérigo e cura das almas e ter feito longa, ainda que não inteira, confissão no período da graça (ANTT/IL Proc.5846:31-35).

Condenado à suspensão das ordens sacras por cinco meses, a pagar 20 cruzados como custas do processo, a penitências espirituais e à confissão geral, o padre Frutuoso Álvares logo tratou de realizar a confissão, o que fez no dia 7 de agosto de 1593 (sendo que sua sentença foi publicada apenas no dia 2 do mesmo mês) ao padre frei Damião Cordeiro, indicado pelo visitador (ANTT/IL Proc.5846:41). Estava o pároco talvez ansioso por livrar sua consciência e salvar sua alma, ou quem sabe apenas queria demonstrar ao visitador sua obediência e submissão ao tribunal? Não é possível saber, embora as opções não sejam excludentes.

Essas são as últimas informações presente no documento sobre o aventuroso padre Frutuoso Álvares. Ao historiador fica a dúvida se ele terá acatado a advertência de Heitor Furtado de Mendonça de se afastar das práticas torpes que tantas vezes o conduziram às barras dos tribunais (no reino, em Cabo Verde e na Bahia) ou se, tão logo embarcou o visitador para Pernambuco, respirou aliviado o sacerdote e reiniciou a trocar tocamentos, abraços, beijos com os jovens de sua freguesia, deleitando-se ao permitir que eles o sodomizassem. A história de vida de Frutuoso talvez reforce a segunda opção, pois até seus 68 anos, nenhum juiz ou confessor conseguira salvar sua alma, retirando-lhe o gosto pelo pecado nefando.

A dúvida do historiador é ainda mais profunda. Pode ser dito que o padre era homossexual? Em nenhum momento de suas confissões, pareceu ele dar mais sentido aos seus atos com tantos jovens que não lhes sabia mais os nomes que não o prazer sentido por sua Carne e a culpa por sua alma e consciência. Em seu cotidiano, tampouco, e pelo que se pode vislumbrar por seus relatos, vivia ele de modo que seu gênero, perfomativamente reiterado em

no século XVI, enquanto em Genebra 31 foram executados entre 1444 e 1789 e, na Holanda, somente em um julgamento entre 1730 e 1732, 70 sodomitas foram executados. MOTT, Luiz. Pagode português. A subcultura gay em Portugal nos tempos inquisitoriais. P.122-123. 
cada ato e em cada momento de sua existência, destoasse daqueles de outros homens em condições análogas - daí suas amizades duradouras com vários homens, eles próprios senhores viris em suas casas. As práticas sexuais do padre Frutuoso Álvares parecem surgir mais como desvios morais que, pesando-lhe na consciência como pecados que ele sabia que eram, não os podia evitar, pois fraca era a Carne perante os artifícios do mal. O vigário do Matoim, destarte, parecia antes assumir seus pecados do que uma identidade sexual que, aliás, dificilmente existia cultural e socialmente para tal.

\section{Referências Bibliográficas}

\section{Fontes Primárias}

Bíblia Sagrada. Rio de Janeiro: Catholic Press, 1967. (Barsa).

Ordenações Afonsinas: http://www1.ci.uc.pt/ihti/proj/afonsinas/

Processo do Padre Frutuoso Álvares. ANTT: PT-TT-TSO/IL/28/5846. Disponível em: http://ttonline.dgarq.gov.pt/dserve.exe?dsqServer=calm6\&dsqIni=Dserve.ini\&dsqApp=Archive\&dsqCmd=show $. \mathrm{tcl} \& \mathrm{dsqDb}=$ Catalog \&dsqPos $=34 \& \mathrm{dsqSearch}=\left(\left((\right.\right.$ text $)=$ 'frutuoso' $\left.^{\prime}\right) \mathrm{AND}\left((\right.$ text $)=$ 'alvares $\left.\left.^{\prime}\right)\right)$.

VAINFAS, Ronaldo. (Org.). Confissões da Bahia: santo ofício da inquisição de Lisboa. São Paulo: Companhia das Letras, 1997.

\section{Livros, capítulos, artigos}

ALMEIDA, Miguel Vale de. Senhores de Si: Uma interpretação antropológica da masculinidade. $2^{\mathrm{a}}$ ed. Lisboa: Fim de Século Edições, 2000.

BARBO, Daniel. O Triunfo do Falo: Homoerotismo, Dominação, Ética e Política na Atenas Clássica. Rio de Janeiro: E-Papers, 2008.

A emergência da homossexualidade: cultura grega, cientificismo e engajamento. In:. História, literatura e homossexualidade. $1^{\text {a }}$ ed. Belo Horizonte: Fino Traço, 2013.

BELLINI, Lígia. A coisa obscura. Mulher, sodomia e Inquisição no Brasil colonial. São Paulo: Editora Brasiliense, 1989.

BETHENCOURT, Francisco. História das Inquisições. Portugal, Espanha e Itália, séculos XV-XIX. São Paulo: Companhia das Letras, 2000.

BOSWELL, John. Christianity, social tolerance and homosexuality. The University of Chicago Press: Chicago; London, 1980.

BUTLER, Judith. Problemas de gênero. Feminismo e subversão da identidade. Rio de Janeiro: Civilização Brasileira, 2012. (Sujeito e história).

CONNELL, R. W. Masculinities.2 $2^{\mathrm{a}}$ ed. Berkeley; Los Angeles, Califórnia: University of California Press: 2005.

COSTA, Jurandir Freire. A inocência e o vício: estudos sobre homoerotismo. Rio de Janeiro: Relume Dumara, 1992.

FEITLER, Bruno. A ação da Inquisição no Brasil: uma tentativa de análise. In: Travessias inquisitoriais das Minas Gerais aos cárceres do Santo Ofício. Belo Horizonte: Fino Traço, 2013.

FIGARI, Carlos. @s outr@s cariocas. Interpelações, experiências e identidades homoeróticas no Rio de Janeiro. Séculos XVII ao XX. Belo Horizonte: Editora UFMG; Rio de Janeiro: IUPERJ, 2007.

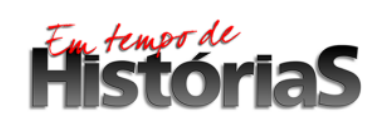


FOUCAULT, Michel. História da sexualidade 1. A vontade de saber. Lisboa: Antropos, Relógios d'água, 1977.

GARCIA, David Córdoba. Teoría queer: reflexiones sobre sexo, sexualidad e identidad. Hacia uma politización de la sexualidad. In: Teoría Queer. Barcelona, Madrid: Editorial Egales, 2007. P. 21-66.

HALPERIN, David. One hundred years of homosexuality and other essays on Greek love. New York: Routledge, 1980.

LE GALL, Jean-Marie. A virilidade dos clérigos. In: CORBIN, Alain; COURTINE, Jean-Jacques; VIGARELLO, Georges. (Orgs.). História da virilidade 1. A invenção da virilidade da Antiguidade às Luzes. Petrópilis, RJ: Editora Vozes, 2013, p.242-263.

MOTT, Luiz. Escravidão, Homossexualidade e Demonologia. São Paulo: Ícone, 1988.

O sexo proibido. Virgens, gays e escravos nas garras da Inquisição, Campinas, SP, Papirus, 1988.

. Pagode português. A subcultura gay em Portugal nos tempos inquisitoriais. IN: Ciência e Cultura. Vol. 40.1988. P. 120-139.

Sodomia não é heresia: dissidência moral e contracultura. In: A Inquisição em xeque. Temas, controvérsias, estudos de caso, Rio de Janeiro, EdUERJ, 2006, p. 253-266.

SCOTT, Joan. História das Mulheres. In: A escrita da história. São Paulo: Ed. UNESP, 1992. P. 65-98.

VAINFAS, Ronaldo. Trópico dos Pecados. Moral, sexualidade e inquisição no Brasil. Rio de Janeiro: Campus, 1989.

Inquisição como fábrica de hereges: os sodomitas foram exceção?. In: A Inquisição em xeque. Rio de Janeiro, EdUERJ, 2006, p. 267-280. 